\title{
Annular atrophic lichen planus
}

\author{
Sara Mai, Siham Mansouri, ${ }^{\ominus}$ Badr Hassam
}

Department of dermatology, CHU Ibn Sina, Rabat, Morocco

\section{Correspondence to Dr Siham Mansouri,} siham-mnsr@hotmail.fr

Accepted 26 June 2019

\section{DESCRIPTION}

A 35-year-old female patient presented with two years history of very pruritic hyperpigemented lesions on the trunk and upper limbs with progressive centrifugal extension. Physical examination revealed brownish annular plaques with raised well-defined margins and pigmented atrophic centre localized on the trunk, axillae arms and forearms. (figure 1)

A skin biopsy of an active lesion on the axilla was performed and histological examination revealed a dense lichenoid mononuclear infiltrate in the papillary dermis with a rarefaction of elastic fibres and vacuolar degeneration of the basal layer with areas of subepidermal cleavage. The epidermis was flattened with progressive thinning towards the centre (figure 2). Laboratory tests including serology for $\mathrm{B}$ and $\mathrm{C}$ hepatitis were normal.

Based on these findings, the diagnosis of annular atrophic lichen planus (AALP) was made and the patient was treated with high-potency topical corticosteroids and antihistamines with a mild improvement after 6 month of follow-up.

Lichen planus (LP) is a chronic inflammatory disease that can affect the skin, hair, nails and mucosae. Among all clinical subtypes, the AALP is the most uncommon. It shows clinical aspects of both annular and atrophic variants of LP. The first description of an AALP eruption was made by

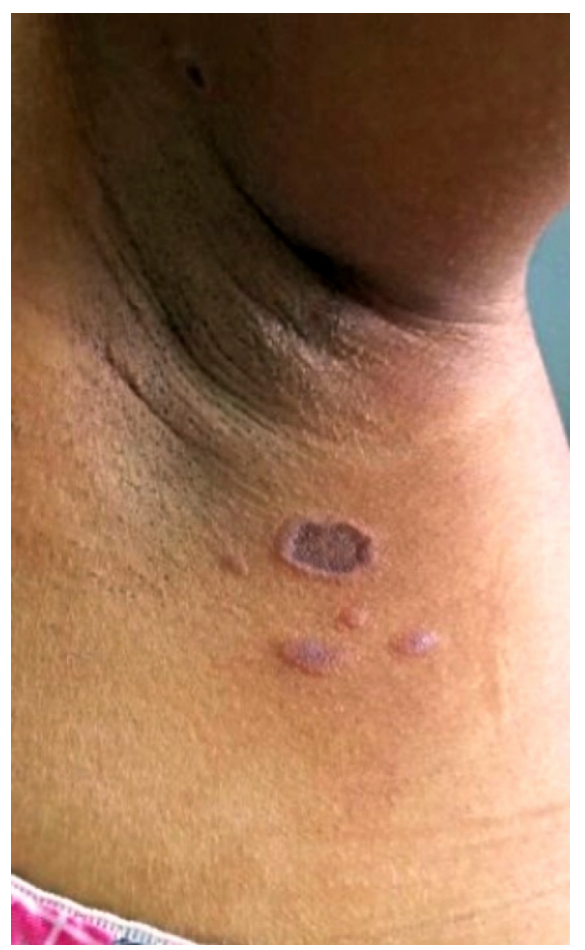

Figure 1 Annular hyperpigmented lesions on the axilla.

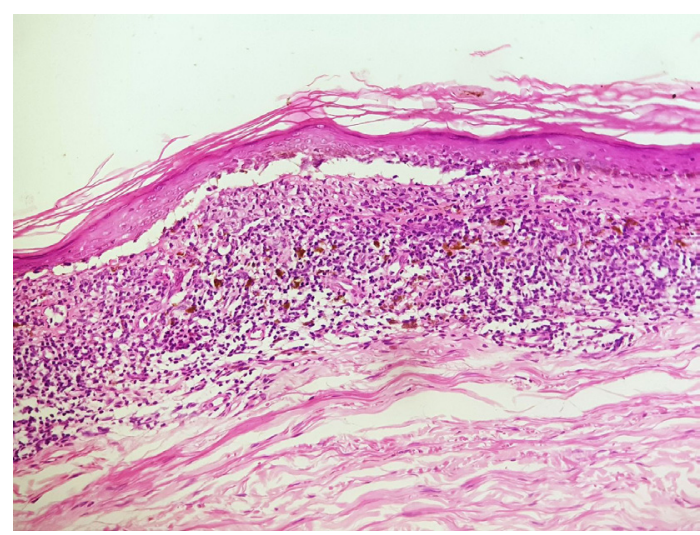

Figure 2 Histopathologic aspect of centre (H\&E, original magnification $\times 100$ ): thin epidermis with loss of rete ridges, vacuolar degeneration of the basal keratinocytes, apoptotic keratinocytes, perivascular and interstitial lymphohistiocytic infiltrate, melanophages and decreased elastic fibres in the upper dermis.

Costello in $1943 .{ }^{1}$ Since then, only few cases have been reported in the literature.

Clinically, it presents as violaceous, annular papules and plaques with a hyperpigmented atrophic centre and raised borders mostly on the trunk and extremities. One case of AALP on the lower lip has been described. All the cases that have been reported were adults. Men and women were equally affected. ${ }^{2}$ Our patient had lesions on the trunk, axillae and upper limbs.

Histopathologically, all typical findings of LP are observed in the margins of the lesions. Whereas the atrophic centre shows a thinned epidermis, with a flattening of rete ridges and a decrease of elastic fibres in papillary dermis. ${ }^{3}$

Topical corticosteroids, calcipotriol, calcineurin inhibitors and phototherapy are commonly considered as treatments of choice.

First-line systemic therapies include acitretin, isotretinoin, methotrexate, systemic corticosteroids, hydroxylchloroquine and dapsone. Cyclosporine, azathioprine and mycophenolate mofetil are considered as second-line treatment options.

\section{Learning points}

- Annular atrophic lichen planus is a particular form of lichen planus (LP) characterised by its unique clinical and pathological features.

- The few cases reported so far are not sufficient to clearly define this particular entity.

- The main challenge of this type of LP is its poor response to the usual topical and systemic treatments. 
Nevertheless, acitretin is the only systemic agent for LP that has achieved level A evidence. $^{4}$

AALP tend to be resistant to topical treatment, phototherapy and immunosuppressive agents. It has been suggested that early treatment has better outcome. Lesions usually heal with hyperpigmentation and scaring. Association of acitritin and hydroxychlorochine has recently shown good results in one case report. ${ }^{5}$

Contributors SaM: contributed in conception, design and drafting of the article, participated in patient's care. SiM: contributed in conception, design and drafting of the article. BH: made corrections and revisions.

Funding The authors have not declared a specific grant for this research from any funding agency in the public, commercial or not-for-profit sectors.
Competing interests None declared.

Patient consent for publication Obtained.

Provenance and peer review Not commissioned; externally peer reviewed.

\section{REFERENCES}

1 Costello MJ. Generalized annular atrophic lichen planus eruption due to quinacrine hydrochloride. Arch Derm Syphilol 1948;57(3 Pt 2):551-4.

2 Morales-Callaghan A, Martínez G, Aragoneses H, et al. Annular atrophic lichen planus. J Am Acad Dermatol 2005;52:906-8.

3 Kim BS, Seo SH, Jang BS, et al. A case of annular atrophic lichen planus. J Eur Acad Dermatol Venereol 2007;21:989-90.

4 Tamer F, Orenay OM, Sarifakioglu E, et al. Annular atrophic lichen planus: a rare clinical entity. J Dtsch Dermatol Ges 2017;15:831-2.

5 Eyler JT, Garib G, Thompson KR, et al. Annular atrophic lichen planus responds to hydroxychloroquine and acitretin. Cutis 2017;100:119-22.

Copyright 2019 BMJ Publishing Group. All rights reserved. For permission to reuse any of this content visit

https://www.bmj.com/company/products-services/rights-and-licensing/permissions/

BMJ Case Report Fellows may re-use this article for personal use and teaching without any further permission.

Become a Fellow of BMJ Case Reports today and you can:

Submit as many cases as you like

- Enjoy fast sympathetic peer review and rapid publication of accepted articles

Access all the published articles

Re-use any of the published material for personal use and teaching without further permission

\section{Customer Service}

If you have any further queries about your subscription, please contact our customer services team on +44 (0) 2071111105 or via email at support@bmj.com.

Visit casereports.bmj.com for more articles like this and to become a Fellow 